\title{
Safety and efficacy of hetrombopag in patients with chronic immune thrombocytopenia: a single-arm, open-label, multi-center phase 1 study
}

\author{
Heng Mei ${ }^{1}$, Xiequn Chen ${ }^{2}$, Jianfeng Zhou ${ }^{3}$, Jianmin $\mathrm{Luo}^{4}$, Qingzhi Shi ${ }^{5}$, Jing Liu ${ }^{6}$, Depei $\mathrm{Wu}^{7}$, \\ Guoan Chen ${ }^{8}$, Yanfei Tai ${ }^{9}$, Junye Xiong ${ }^{9}$, Jianjun Zou' ${ }^{9}$, Yu Hu ${ }^{1}$
}

${ }^{1}$ Department of Hematology, Union Hospital, Tongji Medical College, Huazhong University of Science and Technology, Wuhan, China; ${ }^{2}$ Hematology Department, The First Affiliated Hospital of Air Force Medical University, Xi'an, China; ${ }^{3}$ Hematology Department, Tongji Hospital, Tongji Medical College, Huazhong University of Science and Technology, Wuhan, China; ${ }^{4}$ Hematology Department, The Second Hospital of Hebei Medical University, Shijiazhuang, China; ${ }^{5}$ Hematology Department, The Second Affiliated Hospital of Nanchang University, Nanchang, China; ${ }^{6}$ Hematology Department, The Third Xiangya Hospital of Central South University, Changsha, China; ${ }^{7}$ Hematology Department, The First Affiliated Hospital of Soochow University, Suzhou, China; ${ }^{8}$ Hematology Department, The First Affiliated Hospital of Nanchang University, Nanchang, China; ${ }^{9}$ Department of Clinical Development, Jiangsu Hengrui Pharmaceuticals Co., Ltd., Shanghai, China

Contributions: (I) Conception and design: Y Hu, J Xiong, J Zou; (II) Administrative support: Y Hu, J Xiong, J Zou; (III) Provision of study materials or patients: J Xiong; (IV) Collection and assembly of data: H Mei, X Chen, J Zhou, J Luo, Q Shi, J Liu, D Wu, G Chen, J Xiong, J Zou, Y Hu; (V) Data analysis and interpretation: Y Tai; (VI) Manuscript writing: All authors; (VII) Final approval of manuscript: All authors.

Correspondence to: Prof. Yu Hu, MD. Department of Hematology, Union Hospital, Tongji Medical College, Huazhong University of Science and Technology, 1277 Jiefang Avenue, Wuhan 430022, China. Email: dr_huyu@126.com.

Background: Thrombopoietin receptor agonists (TPO-RAs) are promising therapeutic strategy for patients with immune thrombocytopenia (ITP). We conducted this phase 1 trial (NCT02614846) to evaluate the preliminary efficacy and safety of hetrombopag (a TPO-RA) in patients with ITP.

Methods: Patients with ITP who had an insufficient response or had progressed on at least one standard treatment for ITP were given hetrombopag orally at an initial dose of $5 \mathrm{mg}$ once daily for up to 6 weeks. The primary endpoint was the proportion of patients who achieved platelet counts of $\geq 50 \times 10^{9} / \mathrm{L}$ at week 6 .

Results: A total of 37 eligible patients received hetrombopag treatment. This study met its primary endpoint, 22 (59.5\%, 95\% CI: 42.1-75.3) patients responded to hetrombopag, achieving platelet counts $\geq 50 \times 10^{9} / \mathrm{L}$ at week 6 . Of the 29 (78.4\%, 95\% CI: 61.8-90.2\%) patients who responded at least once during the study, the median time from treatment initiation to first response was 2.1 weeks (95\% CI: $1.3-4.1$ weeks). The median accumulative response duration was 3.1 weeks [interquartile range (IQR), 2.1-4.1 weeks]. The incidence of bleeding was reduced with hetrombopag treatment compared to the baseline. Adverse events (AEs) occurred in 32 (86.5\%) patients and treatment-related AEs occurred in 13 (35.1\%) patients. Two (5.4\%) serious AEs were reported, but neither were treatment related. The dose was modified in one (2.7\%) patient due to an AE. There were no incidences of treatment discontinuation/interruption or death.

Conclusions: Hetrombopag showed preliminary activity in elevating platelet counts and reducing bleeding in patients with chronic ITP who had received at least one standard therapy. It was well-tolerated.

Keywords: Hetrombopag; immune thrombocytopenia (ITP); thrombopoietin receptor; hematologic response; clinical trial

Submitted Aug 19, 2021. Accepted for publication Dec 06, 2021.

doi: $10.21037 / \mathrm{atm}-21-4361$

View this article at: https://dx.doi.org/10.21037/atm-21-4361 


\section{Introduction}

Immune thrombocytopenia (ITP) is an autoimmune disorder which the immune system attacks and destroys platelets, leading to the destruction and impaired production of platelets $(1,2)$. ITP is characterized by thrombocytopenia which results in an increased risk of bleeding (3). Some patients with ITP have no symptoms or only slight bruising; however, others may experience lifethreatening bleeding (3). The aim of managing chronic ITP is to maintain a target platelet level of $>30 \times 10^{9} / \mathrm{L}$, since a platelet level below $30 \times 10^{9} / \mathrm{L}$ indicates an increased risk of bleeding (4-6). Corticosteroids and intravenous immunoglobulins (IVIGs) are the standard first-line therapy for patients with ITP, and have a response rate of $70-90 \%(7)$.

For ITP patients who relapsed or refractory to firstline standard therapy, splenectomy has been the most commonly used second-line treatment for a few decades $(7,8)$. However, as splenectomy may be associated with poor clinical outcomes and adverse events (AEs), such as post-operative morbidity and an increased risk of infections, its clinical application is decreasing (9-11). The stimulation of platelet production by thrombopoietin receptor agonists (TPO-RAs) provides a promising therapeutic option for patients with ITP (8). The development of eltrombopag and avatrombopag [both of which are small-molecule TPO-RAs that bind to the transmembrane site of the thrombopoietin receptor (TPO-R)], and romiplostim (a peptibody that binds directly and competitively to the TPO binding site), revolutionized the clinical management of ITP patients (12-16). A recombinant human TPO (rhTPO) has also been licensed in China in adults and children with ITP (17-19). These drugs are effective in increasing platelet counts and reducing bleeding, but safety concerns still hamper their use in clinical practice (8).

Hetrombopag is a novel orally bioavailable small-molecule TPO-RA that was developed to increase platelet counts (20-22). It is produced by structural modifications to eltrombopag to enhance potency and minimize toxicity. Preclinical studies have shown that hetrombopag has a similar mechanism of action as eltrombopag, but its pharmacological performance in vivo (nude mice) is superior to that of eltrombopag (23). In the first-in-patient study, hetrombopag was found to be well-tolerated and have preliminary efficacy in ITP patients (24). Thus, we conducted this phase 1 trial
(NCT02614846) to further assess the activity and safety of hetrombopag in ITP patients who had an insufficient response or had progressed on a previous standard ITP treatment. We present the following article in accordance with the TREND reporting checklist (available at https:// atm.amegroups.com/article/view/10.21037/atm-21-4361/rc).

\section{Methods}

\section{Study design and participants}

A single-arm, open-label, multi-center, phase 1 study was conducted. Patients were enrolled in this study between August 12, 2015 and November 11, 2016 from 8 sites in China (see Table S1). Patients were considered eligible to participate in this study if they were aged 18-65 years, had been diagnosed with chronic ITP (not including myelodysplastic syndrome, systemic lupus erythematosus, early aplastic anemia, atypical aplastic anemia, thrombotic thrombocytopenic purpura, or pseudothrombocytopenia), had a baseline platelet count $<30 \times 10^{9} / \mathrm{L}$, and had an insufficient response or had progressed on at least one previous treatment for ITP (including but not limited to corticosteroids, intravenous gamma globulin or anti-D IVIG, azathioprine, danazol, cyclophosphamide, immunomodulators, or splenectomy). Further, previous rescue treatment for ITP had to have been completed at least 2 weeks before enrollment. Immunosuppressive maintenance therapy was permitted provided the doses were stable for at least 4 weeks before enrollment.

Patients were excluded from the study if they had received eltrombopag or any other TPO-RA treatment within 30 days before enrollment, had arterial or venous thrombosis, malignant disease, or cardiac disease, had participated in other clinical trials, were pregnant or nursing, had undergone rituximab treatment or splenectomy within 6 months before the study, had human immunodeficiency virus infection, or hepatitis $B$ or $C$ virus infection (Appendix 1).

This study was conducted in accordance with the Declaration of Helsinki (as revised in 2013) and the Good Clinical Practice Guidelines. The protocol and all amendments were approved by the institutional review board or independent ethics committee at each study site (see Table S1). All patients provided written informed consent. This trial is registered with ClinicalTrials.gov (identifier NCT02614846). 


\section{Procedures}

All eligible patients were given hetrombopag orally at an initial dose of $5 \mathrm{mg}$ once daily after overnight fasting ( $>8$ hours of fasting) and at least 2 hours before a meal $(21,25)$. The hetrombopag treatment lasted 6 weeks. Platelet counts were evaluated twice per week. The dose of hetrombopag could be modified (to $2.5,3.75,5$, or $7.5 \mathrm{mg}$ once daily) on the basis of the platelet count of patients after 2 weeks of administration. The dose modification scheme is presented in Table S2. If the platelet count fluctuated sharply within the first 2 weeks, the dose could be modified ahead of schedule. Doses could also be modified according to the investigator's judgement.

Patients were allowed to receive concomitant ITP treatment, including but not limited to corticosteroids, azathioprine, danazol, cyclosporin A, or mycophenolate mofetil. Rescue treatment for ITP was permitted on the basis of investigator judgement, which referred to treatments for increasing platelet count, including drug, platelet transfusion, splenectomy, or dose increase of baseline combination therapy for ITP.

From the first administration of hetrombopag, the researchers compared the returned hetrombopag with the dose information recorded by the patients and the prescription at each visit (except the follow-up visit) to assess compliance. If a patient failed to take hetrombopag or failed to follow the investigator's prescription for $>5$ consecutive days or $\geq 20 \%$ of the total days, the patient was recorded as having deviated from protocol.

\section{Assessment}

Patients were assessed for safety and efficacy weekly during the 6-week treatment period. Safety was followed up within 2 weeks after the last dose of hetrombopag, and any $\mathrm{AE}$ within 4 weeks was recorded. AEs were graded according to the National Cancer Institute Common Terminology Criteria for Adverse Events (v.4.0). The severity of bleeding symptoms was graded according to the World Health Organization (WHO) bleeding scale (grade 0: no bleeding; grade 1: petechiae; grade 2: mild blood loss; grade 3, gross blood loss; grade 4: debilitating blood loss).

\section{Outcomes}

The primary endpoint was the proportion of patients who achieved platelet counts $\geq 50 \times 10^{9} / \mathrm{L}$ at week 6 after the initiation of hetrombopag treatment. The secondary endpoints included the proportion of patients with a platelet count $\geq 50 \times 10^{9} / \mathrm{L}$ at least once, the proportion of patients with a platelet count $\geq 30 \times 10^{9} / \mathrm{L}$ and at least twice the baseline amount, the time from treatment initiation to the first occurrence of a platelet count $\geq 50 \times 10^{9} / \mathrm{L}$, the total duration of a platelet count $\geq 50 \times 10^{9} / \mathrm{L}$, the incidence and severity of bleeding, and safety.

\section{Statistical analysis}

We estimated that $60 \%$ of patients would respond to hetrombopag (i.e., have a platelet count $\geq 50 \times 10^{9} / \mathrm{L}$ at week 6) (26). The null hypothesis defined in this study was that $30 \%$ of patients would respond to hetrombopag. Thus, a sample size of 23 patients was needed to provide $80 \%$ power at a type I error of 0.025 (1-sided) using the exact method. Allowing for a $20 \%$ dropout rate, 29 patients had to be enrolled.

Both full analysis set (FAS) and safety set (SS) included all patients who received at least one dose of hetrombopag. The FAS was used as the primary population for the efficacy analysis, and the SS was used for the safety analysis. Descriptive statistics were used to summarize the baseline demographic and clinical characteristics of the patients, the duration of platelet counts $\geq 50 \times 10^{9} / \mathrm{L}$, and safety data. Proportions in the primary and secondary endpoints were reported with their exact $95 \%$ CIs calculated using Clopper-Pearson methods. The median time from treatment initiation to the first occurrence of a platelet count $\geq 50 \times 10^{9} / \mathrm{L}$ was estimated and presented with the accompanying $95 \%$ CI. The primary endpoint was analyzed using the last-observation-carried-forward imputation in which the last platelet count after the baseline was used in the subsequent analysis for any patient with a missing follow-up visit value. All the analyses were conducted with SAS software, version 9.4.

\section{Results}

\section{Patient baseline characteristics}

From August 12, 2015 to November 11, 2016, 47 patients were screened, and 37 eligible patients received hetrombopag treatment. All 37 patients completed the 6-week treatment regimen, and were included in the FAS and SS. Patients' baseline demographic and clinical characteristics are presented in Table 1. Patients had a 
Table 1 Baseline characteristics

\begin{tabular}{lc}
\hline Characteristics & Data \\
\hline Age (years) & $40.0(28.0-53.0)$ \\
Gender & $12(32.4 \%)$ \\
Male & $25(67.6 \%)$ \\
Female & $24.0(21.3-25.1)$ \\
Body mass index $\left(\mathrm{kg} / \mathrm{m}^{2}\right)$ & $14.0(11.0-22.0)$ \\
Platelet counts $\left(\times 10^{9} / \mathrm{L}\right)$ & \\
Bleeding $($ WHO bleeding scale) & $18(48.7 \%)$ \\
Total & $17(45.9 \%)$ \\
Grade 1 & $1(2.7 \%)$ \\
Grade 2 & 0 \\
Grade 3 & 0 \\
Grade 4 & $3.1(1.9-9.0)$ \\
Time from diagnosis of ITP (years) & \\
Prior treatment for ITP & $37(100.0 \%)$ \\
Corticosteroid & $13.1 \%)$ \\
Immunosuppressant & \\
Splenectomy & \\
\hline Data are presented as $n(\%)$ or median & \\
\hline
\end{tabular}

Data are presented as n (\%) or median (IQR). ITP, immune thrombocytopenia.

median age of 40.0 years [interquartile range (IQR), 28.0-53.0), and $12(32.4 \%)$ patients were male. The median baseline platelet counts were $14 \times 10^{9} / \mathrm{L}$ (IQR, $\left.11 \times 10^{9}-22 \times 10^{9}\right)$. The median time from diagnosis of ITP to study enrollment was 3.1 years (IQR, 1.9-9.0 years), and 3 (8.1\%) patients had received prior splenectomy.

\section{Efficacy}

This study reached its primary endpoint, with $22(59.5 \%$, 95\% CI: $42.1-75.3 \%$ ) patients achieved a response (i.e., a platelet count $\geq 50 \times 10^{9} / \mathrm{L}$ ) at week 6 after the initiation of treatment (see Table 2). During the 6-week treatment period, 29 (78.4\%, 95\% CI: 61.8-90.2\%) patients had a platelet count $\geq 50 \times 10^{9} / \mathrm{L}$ at least once. The median platelet count increased from $14 \times 10^{9} / \mathrm{L}\left(\mathrm{IQR}, 11 \times 10^{9}-22 \times 10^{9}\right)$ at baseline to $55 \times 10^{9} / \mathrm{L}\left(\mathrm{IQR}, 26 \times 10^{9}-150 \times 10^{9}\right)$ at week 2 , and remained several-fold higher than that of baseline thereafter (see Figure 1). For the 29 responders, the median time from treatment initiation to the first response was 2.1 weeks ( $95 \%$
CI: 1.3-4.1). The median accumulative response duration was 3.1 weeks (IQR 2.1-4.1). Sixteen (43.2\%) patients had an accumulative response duration $\geq 3$ weeks and $8(21.6 \%)$ patients had an accumulative response duration $\geq 4$ weeks. Thirty-three (89.2\%, 95\% CI: 74.6-97.0\%) patients met both criteria of reaching a platelet count $\geq 30 \times 10^{9} / \mathrm{L}$ and at least twice the baseline amount during 6-week treatment period.

Grade 1-4 bleeding symptoms occurred in 18 (48.7\%) of the 37 patients at the time of baseline visit, but only occurred in $6(16.2 \%)$ patients at week 6 after hetrombopag treatment. Throughout the treatment period, 15 patients experienced grade 1-4 bleeding, and 5 patients experienced grade 2-4 bleeding (see Figure 2). An obvious decrease in the incidence of bleeding occurred rapidly after treatment, and this decrease continued to be maintained from weeks 3-6. This reduction was mainly driven by a decrease in grade 1 bleeding. The trend of decreased bleeding incidence was in line with that of increased platelet counts throughout the treatment period.

\section{Safety}

The median compliance rate was $100.0 \%$ in the 37 patients receiving hetrombopag treatment. The final dose was $2.5 \mathrm{mg}$ once every other day in $1(2.7 \%)$ patient, $2.5 \mathrm{mg}$ once daily in $4(10.8 \%)$ patients, $3.75 \mathrm{mg}$ once daily in 4 (10.8\%) patients, $5 \mathrm{mg}$ once daily in $9(24.3 \%)$ patients, and $7.5 \mathrm{mg}$ once daily in $19(51.4 \%)$ patients (see Table S3).

AEs occurred in $32(86.5 \%)$ patients, the most common ones being upper respiratory tract infection (12 patients, $32.4 \%)$, increased alanine aminotransferase (8 patients, $21.6 \%$ ), increased blood lactate dehydrogenase (6 patients, $16.2 \%$ ), and skin hemorrhage (5 patients, $13.5 \%$ ) (see Tables 3,4). Treatment-related AEs were reported in 13 (35.1\%) patients. The common treatment-related AEs were increased blood lactate dehydrogenase (5 patients, $13.5 \%$ ), increased alanine aminotransferase (4 patients, $10.8 \%$ ), increased aspartate aminotransferase (2 patients, $5.4 \%$ ), and increased blood uric acid (2 patients, 5.4\%) (see Table S4). Four (10.8\%) patients experienced grade 3 or 4 AEs. Among these patients, 2 (5.4\%) AEs were considered treatment related (1 patient had increased alanine aminotransferase and 1 had hyperuricemia). One patient experienced dose reduction due to peripheral and facial edema, and this $\mathrm{AE}$ was considered treatment related. No patient discontinued or interrupted treatment due to AEs. Serious AEs occurred in $2(5.4 \%)$ patients, including 1 patient with a decreased 
Table 2 Efficacy outcomes

\begin{tabular}{|c|c|}
\hline Outcomes & Data \\
\hline Proportion of patients achieving platelet counts $\geq 50 \times 10^{9} / \mathrm{L}$ at least once & $29(78.4 \%, 61.8-90.2 \%)$ \\
\hline \multicolumn{2}{|l|}{ Duration from treatment initiation to the first response } \\
\hline $\mathrm{n}$ & 29 \\
\hline \multicolumn{2}{|l|}{ Duration of accumulative response } \\
\hline $\mathrm{n}$ & 29 \\
\hline Median (IQR), weeks & $3.1(2.1-4.1)$ \\
\hline$\geq 3$ weeks & $16(43.2 \%)$ \\
\hline \multicolumn{2}{|l|}{ Bleeding throughout the treatment period (WHO bleeding scale) } \\
\hline Total & $15(40.5 \%)$ \\
\hline Grade 1 & $10(27.0 \%)$ \\
\hline Grade 2 & $5(13.5 \%)$ \\
\hline Grade 3 & 0 \\
\hline Grade 4 & 0 \\
\hline
\end{tabular}

Data are presented as $\mathrm{n}(\%), \mathrm{n}(\%, 95 \% \mathrm{Cl})$, median $(95 \% \mathrm{Cl})$, or median (IQR).

platelet count and 1 with gingival bleeding, but neither of these AEs were related to hetrombopag treatment. No deaths were reported.

\section{Discussion}

In this study, we evaluated the efficacy and safety of hetrombopag in patients who had undergone at least one previous treatment for ITP. This study reached its primary endpoint; that is, $59.5 \%$ (95\% CI: $42.1-75.3 \%, 22 / 37)$ of patients achieved a platelet count of $\geq 50 \times 10^{9} / \mathrm{L}$ at week 6 following the initiation of hetrombopag treatment. The accumulative response duration was 3.1 weeks (IQR, 2.14.1 weeks). Hetrombopag had a tolerable and manageable safety profile in patients with ITP.

As the first oral TPO-RA, eltrombopag had a response rate (achieving a platelet count of $\geq 50 \times 10^{9} / \mathrm{L}$ after 6 weeks treatment) of $57.7 \%(60 / 104)$ in patients with ITP in a Chinese study (27), 60\% (9/15) in a Japanese study (28), and $59 \%(43 / 73)$ and $79 \%(106 / 135)$ in two international phase
3 studies $(26,29)$. We found that hetrombopag had a similar response rate $(59.5 \%)$ to that of eltrombopag after 6 weeks of treatment. Patients' platelet counts rapidly increased after treatment, and were maintained thereafter during the hetrombopag treatment period. Cross-trial comparisons should be interpreted with caution due to different patient populations included; however, these results indicate that hetrombopag shows promise in upregulating platelet counts.

The main goal of treatment of chronic ITP is to prevent bleeding symptoms. In this study, the bleeding status of patients during the screening and trial period was evaluated according to the WHO bleeding scale. The results showed that the bleeding symptoms of patients were clinically improved after hetrombopag treatment. The incidence of bleeding decreased with the increase of platelet counts after hetrombopag treatment, a phenomenon that has also been observed in previous eltrombopag studies (26-28). No uncontrolled bleeding occurred.

The safety of hetrombopag was manageable. During the treatment period, most patients $(29,78.4 \%)$ only 


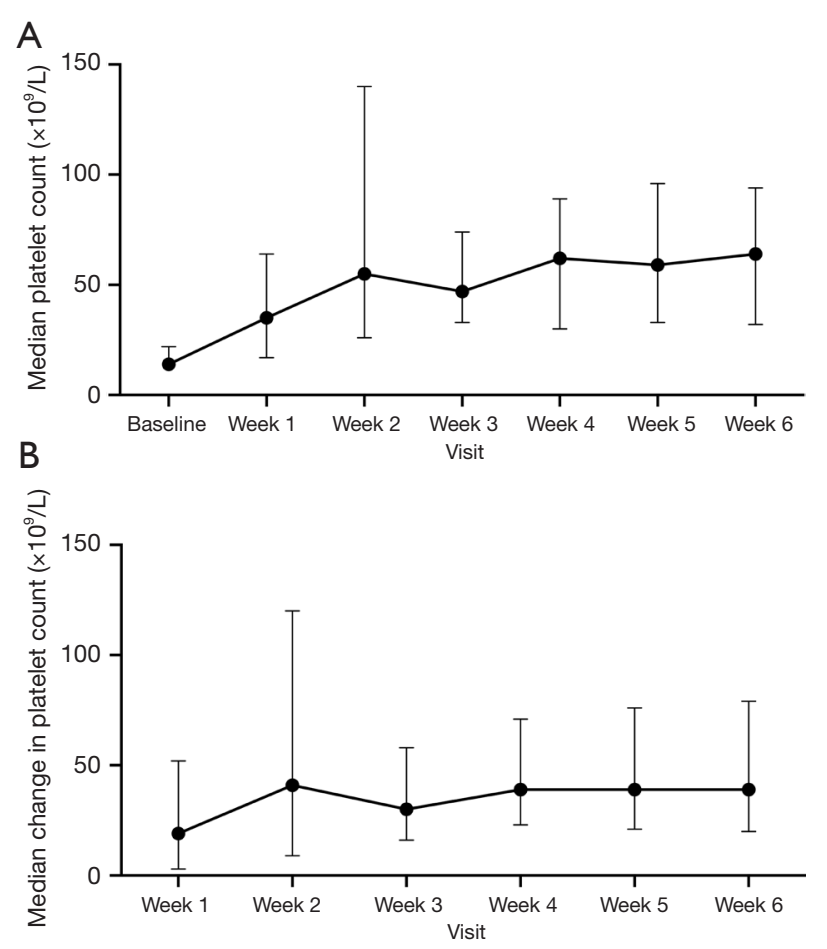

Figure 1 Median platelet counts (A) and median changes in platelet counts (B) at each visit.

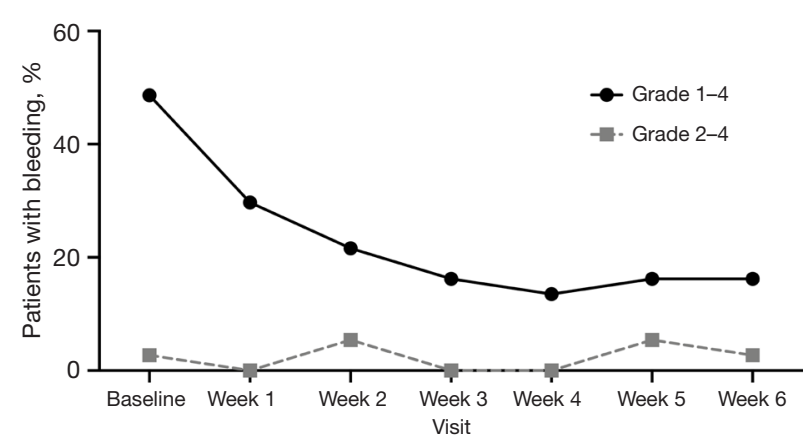

Figure 2 Proportion of patients with bleeding during hetrombopag treatment.

required a dose modification once or twice. Two patients had $>5$ dose modifications, and 2 patients did not require dose modification. After dose adjustment, the changes of platelet count were stable and the toxicities of hetrombopag were tolerable. We found the mean dose of hetrombopag was $5.5 \mathrm{mg}$ but the final dose in most patients was $7.5 \mathrm{mg}$, which may indicate that the dose demand for patients with chronic ITP is a little bit high. Only one patient's dose of hetrombopag was modified due to an AE. Liver toxicity
Table 3 Adverse events

\begin{tabular}{lc}
\hline Adverse events & Data \\
\hline Adverse events of any cause & $32(86.5 \%)$ \\
Grade 3 or higher & $4(10.8 \%)$ \\
Serious & $2(5.4 \%)$ \\
Leading to dose reduction/treatment & $1(2.7 \%)$ \\
interruption & 0 \\
Leading to treatment discontinuation & 0 \\
Leading to death & $13(35.1 \%)$ \\
$\begin{array}{l}\text { Treatment-related adverse events* } \\
\text { Grade } 3 \text { or higher }\end{array}$ & $2(5.4 \%)$ \\
$\begin{array}{l}\text { Serious } \\
\text { Leading to dose reduction/treatment }\end{array}$ & 0 \\
interruption & $1(2.7 \%)$ \\
Leading to treatment discontinuation & 0 \\
Leading to death & 0 \\
\hline $\begin{array}{l}\text { Data are presented as } \mathrm{n} \text { (\%). *, the treatment-related adverse } \\
\text { events refers to the correlation of the adverse events with } \\
\text { study treatment was "definitely related", "possibly related", or } \\
\text { "unassessable", as judged by investigators. }\end{array}$
\end{tabular}

in this study was not a new safety signal since it had been observed in a previous first-in-patient trial of hetrombopag in ITP patients (24). In the current study, most of the treatment-related increased transaminases were grades $1-2$, and only 1 patient had grade 3 increased alanine aminotransferase. The increased alanine aminotransferase in all patients returned to normal after appropriate liver-protection treatment, and did not lead to dose reduction, or treatment interruption or discontinuation. A thromboembolic event was an eltrombopag-related $\mathrm{AE}$, which was reported in patients on day 42 after eltrombopag treatment (12). In the present hetrombopag study, no thromboemboli were observed.

Cataracts have been observed in rodent studies of eltrombopag (30). In our study, no cataracts were reported, but 1 patient reported visual impairment. That patient had optic atrophy at the baseline and had more serious optic atrophy at his last scheduled visit for the study. This patient was given vitamin B1 and mecobalamin tablets, and his optic atrophy was relieved 1 week later. The aggravation of his optic atrophy was considered treatment related. It should be noted that the limited follow-up duration of this study may not be enough to detect AEs such as cataract. Results 
Table 4 Adverse events occurring in $\geq 5 \%$ of patients

\begin{tabular}{|c|c|c|}
\hline Adverse events & Any grade & Grade 3-4 \\
\hline Alanine aminotransferase increased & $8(21.6 \%)$ & $1(2.7 \%)$ \\
\hline Blood lactate dehydrogenase increased & $6(16.2 \%)$ & 0 \\
\hline Skin hemorrhage & $5(13.5 \%)$ & 0 \\
\hline Lymphocyte morphology abnormal & $3(8.1 \%)$ & 0 \\
\hline Aspartate aminotransferase increased & $3(8.1 \%)$ & 0 \\
\hline Gingival bleeding & $3(8.1 \%)$ & $1(2.7 \%)$ \\
\hline Hyperuricemia & $3(8.1 \%)$ & $1(2.7 \%)$ \\
\hline Blood uric acid increased & $2(5.4 \%)$ & 0 \\
\hline Blood glucose increased & $2(5.4 \%)$ & 0 \\
\hline Nausea & $2(5.4 \%)$ & 0 \\
\hline Headache & $2(5.4 \%)$ & 0 \\
\hline Alopecia & $2(5.4 \%)$ & 0 \\
\hline Hypokalemia & $2(5.4 \%)$ & 0 \\
\hline Arthralgia & $2(5.4 \%)$ & 0 \\
\hline Epistaxis & $2(5.4 \%)$ & 0 \\
\hline
\end{tabular}

Data are presented as $\mathrm{n}(\%)$.

with longer follow-ups can be found in the phase 3 trial in patients with ITP (31). In that study, 1 of 339 patients developed cataract during the 24 weeks of hetrombopag treatment.

It should be noted that the recommended dose of eltrombopag varies according to the characteristics of different ethnic groups. The recommended initial dose of eltrombopag for ITP is $50 \mathrm{mg}$ once daily in American patients, $12.5 \mathrm{mg}$ once daily in Japanese patients, and $25 \mathrm{mg}$ once daily in Chinese patients (26-28,30). Thus, different starting doses need to be considered when extrapolating the use of hetrombopag to populations in other parts of the world.

Despite these promising results, our study had several limitations. First, this was a single-arm phase 1 study and the sample size was small. Second, as the treatment duration was only 6 weeks, no evidence was gathered about the long-term efficacy and safety of hetrombopag. Third, the results of other studies on eltrombopag have shown that the platelet count level cannot be maintained after treatment discontinuation (26-28). In our study, the observation period was short (only 2 weeks after drug discontinuation); thus, it is unknown whether all patients' platelet counts returned to the baseline after hetrombopag discontinuation as occurs with eltrombopag. The above unanswered questions will be further explored in a randomized phase 3 study (NCT03222843).

TPO-RAs including eltrombopag, avatrombopag, and romiplostim have been approved for treating ITP; however, developing new drugs that have a similar mechanism of action to pre-existing drugs is still valuable, as these followon drugs may provide more therapeutic choices (32). In our study, hetrombopag showed preliminary activity in elevating platelet levels and reducing bleeding symptoms in ITP 
patients who had an insufficient response or had progressed on at least one previous treatment for ITP. The toxicity of hetrombopag was tolerable, and no new safety signals were identified. A placebo-controlled phase 3 confirmatory study is currently underway to further assess the safety and efficacy of hetrombopag in ITP patients.

\section{Acknowledgments}

We thank the patients and their families and acknowledge the contributions of all investigators in this trial. We would like to acknowledge Tengfei Zhang (PhD, Medical Writer, Jiangsu Hengrui Pharmaceuticals Co., Ltd.) for medical writing support according to Good Publication Practice Guidelines. We would also like to thank AME Editing Service for the help in polishing our paper.

Funding: This study was funded by Jiangsu Hengrui Pharmaceuticals Co., Ltd.

\section{Footnote}

Reporting Checklist: The authors have completed the TREND reporting checklist. Available at https://atm. amegroups.com/article/view/10.21037/atm-21-4361/rc

Data Sharing Statement: Available at https://atm.amegroups. com/article/view/10.21037/atm-21-4361/dss

Conflicts of Interest: All authors have completed the ICMJE uniform disclosure form (available at https://atm.amegroups. com/article/view/10.21037/atm-21-4361/coif). YT, JX, and $\mathrm{JZ}$ report that they are employees of Jiangsu Hengrui Pharmaceuticals Co., Ltd. All other authors report that this study was funded by Jiangsu Hengrui Pharmaceuticals Co., Ltd. The authors have no other conflicts of interest to declare.

Ethical Statement: The authors are accountable for all aspects of the work in ensuring that questions related to the accuracy or integrity of any part of the work are appropriately investigated and resolved. The study was done in accordance with Declaration of Helsinki (as revised in 2013) and the Good Clinical Practice Guideline. The protocol and all amendments were approved by the institutional review board or independent ethics committee of each study site. All patients provided written informed consent.

Open Access Statement: This is an Open Access article distributed in accordance with the Creative Commons Attribution-NonCommercial-NoDerivs 4.0 International License (CC BY-NC-ND 4.0), which permits the noncommercial replication and distribution of the article with the strict proviso that no changes or edits are made and the original work is properly cited (including links to both the formal publication through the relevant DOI and the license). See: https://creativecommons.org/licenses/by-nc-nd/4.0/.

\section{References}

1. Gernsheimer T, Stratton J, Ballem PJ, et al. Mechanisms of response to treatment in autoimmune thrombocytopenic purpura. N Engl J Med 1989;320:974-80.

2. Ballem PJ, Segal GM, Stratton JR, et al. Mechanisms of thrombocytopenia in chronic autoimmune thrombocytopenic purpura. Evidence of both impaired platelet production and increased platelet clearance. J Clin Invest 1987;80:33-40.

3. Cines DB, Blanchette VS. Immune thrombocytopenic purpura. N Engl J Med 2002;346:995-1008.

4. Cines DB, Bussel JB. How I treat idiopathic thrombocytopenic purpura (ITP). Blood 2005;106:2244-51.

5. Provan D, Arnold DM, Bussel JB, et al. Updated international consensus report on the investigation and management of primary immune thrombocytopenia. Blood Adv 2019;3:3780-817.

6. Neunert C, Terrell DR, Arnold DM, et al. American Society of Hematology 2019 guidelines for immune thrombocytopenia. Blood Adv 2019;3:3829-66. Erratum in: Blood Adv 2020;4:252.

7. Witkowski M, Witkowska M, Robak T. Autoimmune thrombocytopenia: Current treatment options in adults with a focus on novel drugs. Eur J Haematol 2019;103:531-41.

8. Ghanima W, Cooper N, Rodeghiero F, et al. Thrombopoietin receptor agonists: ten years later. Haematologica 2019;104:1112-23.

9. Rodeghiero F. A critical appraisal of the evidence for the role of splenectomy in adults and children with ITP. Br J Haematol 2018;181:183-95.

10. Ghanima W, Godeau B, Cines DB, et al. How I treat immune thrombocytopenia: the choice between splenectomy or a medical therapy as a second-line treatment. Blood 2012;120:960-9.

11. George JN. Management of patients with refractory immune thrombocytopenic purpura. J Thromb Haemost 
2006;4:1664-72.

12. Bussel JB, Cheng G, Saleh MN, et al. Eltrombopag for the treatment of chronic idiopathic thrombocytopenic purpura. N Engl J Med 2007;357:2237-47.

13. Wong RSM, Saleh MN, Khelif A, et al. Safety and efficacy of long-term treatment of chronic/persistent ITP with eltrombopag: final results of the EXTEND study. Blood 2017;130:2527-36. Erratum in: Blood 2018;131:709.

14. Bussel JB, Kuter DJ, Aledort LM, et al. A randomized trial of avatrombopag, an investigational thrombopoietinreceptor agonist, in persistent and chronic immune thrombocytopenia. Blood 2014;123:3887-94.

15. Jurczak W, Chojnowski K, Mayer J, et al. Phase 3 randomised study of avatrombopag, a novel thrombopoietin receptor agonist for the treatment of chronic immune thrombocytopenia. Br J Haematol 2018;183:479-90.

16. Kuter DJ, Bussel JB, Lyons RM, et al. Efficacy of romiplostim in patients with chronic immune thrombocytopenic purpura: a double-blind randomised controlled trial. Lancet 2008;371:395-403.

17. Kong Z, Qin P, Xiao S, et al. A novel recombinant human thrombopoietin therapy for the management of immune thrombocytopenia in pregnancy. Blood 2017;130:1097-103.

18. Mei H, Xu M, Yuan G, et al. A multicentre double-blind, double-dummy, randomised study of recombinant human thrombopoietin versus eltrombopag in the treatment of immune thrombocytopenia in Chinese adult patients. Br J Haematol 2021;195:781-9.

19. Wang S, Yang R, Zou P, et al. A multicenter randomized controlled trial of recombinant human thrombopoietin treatment in patients with primary immune thrombocytopenia. Int J Hematol 2012;96:222-8.

20. Zheng L, Liang MZ, Zeng XL, et al. Safety, Pharmacokinetics and Pharmacodynamics of Hetrombopag Olamine, a Novel TPO-R Agonist, in Healthy Individuals. Basic Clin Pharmacol Toxicol 2017;121:414-22.

21. Yang G, Huang R, Yang S, et al. Effect of postdose fasting duration on hetrombopag olamine pharmacokinetics and pharmacodynamics in healthy volunteers. Br J Clin Pharmacol 2020;86:1528-36.

22. Chen T, Chen Z, Zhang S, et al. Development and validation of a LC-MS/MS method for quantification of hetrombopag for pharmacokinetics study. Springerplus 2015;4:652.

23. Xie C, Zhao H, Bao X, et al. Pharmacological characterization of hetrombopag, a novel orally active human thrombopoietin receptor agonist. J Cell Mol Med 2018;22:5367-77.

24. Wang Z, Chen L, Zhang F, et al. First-in-patient study of hetrombopag in patients with chronic idiopathic thrombocytopenic purpura. J Thromb Haemost 2020;18:3053-60.

25. Wang Z, Chen X, Li A, et al. Effect of Food on the Pharmacokinetic and Pharmacodynamic Profiles of Hetrombopag in Healthy Volunteers. Clin Ther 2020;42:2280-8.

26. Bussel JB, Provan D, Shamsi T, et al. Effect of eltrombopag on platelet counts and bleeding during treatment of chronic idiopathic thrombocytopenic purpura: a randomised, double-blind, placebo-controlled trial. Lancet 2009;373:641-8.

27. Yang R, Li J, Jin J, et al. Multicentre, randomised phase III study of the efficacy and safety of eltrombopag in Chinese patients with chronic immune thrombocytopenia. Br J Haematol 2017;176:101-10.

28. Tomiyama Y, Miyakawa Y, Okamoto S, et al. A lower starting dose of eltrombopag is efficacious in Japanese patients with previously treated chronic immune thrombocytopenia. J Thromb Haemost 2012;10:799-806.

29. Cheng G, Saleh MN, Marcher C, et al. Eltrombopag for management of chronic immune thrombocytopenia (RAISE): a 6-month, randomised, phase 3 study. Lancet 2011;377:393-402.

30. Novartis (2017) Promacta prescribing information. (Accessed Aug 22, 2020). Available online: https://www. novartis.us/sites/www.novartis.us/files/promacta.pdf

31. Mei H, Liu X, Li Y, et al. A multicenter, randomized phase III trial of hetrombopag: a novel thrombopoietin receptor agonist for the treatment of immune thrombocytopenia. J Hematol Oncol 2021;14:37.

32. Hollis A. Me-too drugs: is there a problem. 2004. (Accessed December 11, 2020). Available online: https:// www.who.int/intellectualproperty/topics/ip/MetooDrugs_Hollis1.pdf

Cite this article as: Mei H, Chen X, Zhou J, Luo J, Shi Q, Liu J, Wu D, Chen G, Tai Y, Xiong J, Zou J, Hu Y. Safety and efficacy of hetrombopag in patients with chronic immune thrombocytopenia: a single-arm, open-label, multi-center phase 1 study. Ann Transl Med 2022;10(2):30. doi: 10.21037/atm-214361 


\section{Inclusion criteria}

1) Subjects were $\geq 18$ years of age and $\leq 65$ years of age, with no gender requirement.

2) Pre-screening clinical diagnosis of chronic immune thrombocytopenia (cITP). Platelet count of $<30 \times 10^{9} / \mathrm{L}$ at the time of both screening and pre-administration visit (D0).

3) ITP diagnosed by bone marrow examination carried out within the screening period, excluding myelodysplastic syndrome (MDS), immune diseases such as systemic lupus erythematosus (SLE), early aplastic anemia (AA), atypical aplastic anemia, thrombocytopenic purpura (TTP), pseudo thrombocytopenia, and secondary thrombocytopenia (STP) caused by other reasons.

4) The patient has poor response to at least one ITP therapy or relapses after treatment. Past treatments for chronic ITP include, but are not limited to, corticosteroids, immunomodulators (intravenous gamma globulin or anti-D immunoglobulin), azathioprine, danazol, cyclophosphamide and immunomodulators, and splenectomy.

5) Past rescue treatments for ITP (include but not limited to corticosteroids, immunoglobulins, immunomodulators, and cyclophosphamide) must be completed at least 2 weeks pre-administration (refer to item 4 in inclusion criteria).

6) Patients receiving immunosuppressants (including but not limited to corticosteroids, azathioprine, danazol, cyclosporin A, mycophenolate mofetil) for maintenance treatment must have a stable dose at least 4 weeks before the study.

7) Prothrombin time (PT) does not exceed the normal value range by $\pm 3 \mathrm{~s}$; activated partial thromboplastin time (APTT) does not exceed the normal value range by $\pm 10 \mathrm{~s}$; there was no history of other coagulopathy except ITP.

8) The whole blood cell count was within the reference value range (those with a whole blood cell count exceeding the reference value range can be enrolled if they are judged as "abnormal but not clinically significant" by the Investigator. e.g., abnormalities caused by corticosteroids), but the following conditions should be treated specially:

- Platelet count of $<30 \times 10^{9} / \mathrm{L}$ meets the inclusion criteria.

- Hemoglobin: female and male with $\geq 10 \mathrm{~g} / \mathrm{dL}$ meet the inclusion criteria.

- Those with an absolute neutrophil count (ANC) of $\geq 1,500 / \mu \mathrm{L}\left(1.5 \times 10^{9} / \mathrm{L}\right)$ can be enrolled.

9) Patients with potential fertility (i.e., except for females undergoing hysterectomy, bilateral salpingectomy, bilateral tubal ligation or more than 1 year after menopause; males undergoing bilateral vasectomy) must take effective contraceptive measures in at least two weeks before the first administration of the investigational drug, during the entire study period, and within 28 days after the end of the study (or early study termination).

10) Women with potential fertility must be negative for a pregnancy test during the screening period and on D0 of the study.

11) Understand the study procedures and voluntarily agree to sign the informed consent form in writing.

\section{Exclusion criteria (those who meet any of the followings are ineligible)}

1) The patient has experienced any arterial or venous thrombosis (stroke, transient ischemic attack, myocardial infarction, deep vein thrombosis or pulmonary embolism) or has clinical symptoms and medical history suggesting thromboembolic disorders.

2) History of malignant tumors.

3) Heart disease within the past 3 months, including NHYA grade III/IV congestive heart failure and arrhythmias requiring medical treatment. Or any of the following: arrhythmias (such as atrial fibrillation) known to increase the risk of a thrombotic event, or patients with a corrected QT interval (QTc) of $>450 \mathrm{msec}$ (QTc of $>480 \mathrm{msec}$ for patients with bundle branch block).

4) Pregnant or lactating women.

5) Participated in the treatment of other investigational drugs within 30 days or 5 half-lives (whichever is longer) before the first administration of the investigational drug.

6) Have received within 30 days or 5 half-lives (whichever is longer) before the first administration of the investigational drug or are currently receiving treatment with eltrombopag or any other thrombopoietin receptor agonist.

7) Patients who had received rituximab and splenectomy within 6 months before the first administration of the 
investigational drug.

8) Within 2 weeks before the start of the study, subjects have continuously used medications affecting platelet functions (including but not limited to aspirin, aspirin-containing complexes, clopidogrel, salicylate, and/or non-steroidal antiinflammatory drugs (NSAIDs) or anticoagulants for more than 3 days.

9) Clinical history of all laboratory or clinical HIV infections and past hepatitis C infections, chronic hepatitis B infections, or evidence of active hepatitis found during screening. Laboratory tests carried out during the screening period suggest hepatitis C or hepatitis B infection.

10) The following blood biochemistry indicators: ALT and AST are more than 1.5 times the upper limit of normal; total bilirubin, blood creatinine and alkaline phosphatase are more than 1.2 times the upper limit of normal; serum albumin lower than $10 \%$ the lower limit of normal;

11) Clinical findings of abnormalities other than ITP or any medical history or condition in the screening stage deemed by the Investigator as unsuitable for participation in this study. 
Table S1 Participating sites

\begin{tabular}{|c|c|c|c|}
\hline $\begin{array}{l}\text { Principal } \\
\text { investigator }\end{array}$ & Institution & $\begin{array}{l}\text { Number of } \\
\text { patients }\end{array}$ & $\begin{array}{l}\text { Ethics committee } \\
\text { approval number/ID }\end{array}$ \\
\hline Xiequn Chen & The First Affiliated Hospital of Air Force Medical University, Xi'an, China & 14 & YS20160713-1 \\
\hline Jianfeng Zhou & $\begin{array}{l}\text { Tongji Hospital, Tongji Medical College, Huazhong University of Science and } \\
\text { Technology, Wuhan, China }\end{array}$ & 5 & $2015-110-3$ \\
\hline Jianmin Luo & The Second Hospital of Hebei Medical University, Shijiazhuang, China & 3 & 2015EC10-03-XZ-3 \\
\hline Qingzhi Shi & The Second Affiliated Hospital of Nanchang University, Nanchang, China & 1 & None \\
\hline Hua Lu & $\begin{array}{l}\text { The First Affiliated Hospital of Nanjing Medical University, Jiangsu Province Hospital, } \\
\text { Nanjing, China }\end{array}$ & 1 & 2015-MD-158.A2 \\
\hline
\end{tabular}

Table S2 Dose modification scheme of hetrombopag

\begin{tabular}{|c|c|c|c|c|c|}
\hline Weeks & $\begin{array}{l}\text { Current } \\
\text { dose }\end{array}$ & \multicolumn{4}{|c|}{ Platelet counts } \\
\hline Week 0-2 & $5 \mathrm{mg}$ & $5 \mathrm{mg}$ & $5 \mathrm{mg}$ & reduce to $3.75 \mathrm{mg}$ & $\begin{array}{l}\text { Dose should be interrupted until platelet counts reach } \\
\leq 150 \times 10^{9} / \mathrm{L} \text {, and then } 3.75 \mathrm{mg} \text { was given }\end{array}$ \\
\hline \multirow[t]{4}{*}{ Week 3-6 } & $2.5 \mathrm{mg}$ & increase to $3.75 \mathrm{mg}$ & $2.5 \mathrm{mg}$ & reduce to $2.5 \mathrm{mg}$ & $\begin{array}{l}\text { Dose should be interrupted until platelet counts reach } \\
\leq 150 \times 10^{9} / \mathrm{L} \text {, and then } 2.5 \mathrm{mg} \text { was given }\end{array}$ \\
\hline & $3.75 \mathrm{mg}$ & increase to $5 \mathrm{mg}$ & $3.75 \mathrm{mg}$ & reduce to $2.5 \mathrm{mg}$ & $\begin{array}{l}\text { Dose should be interrupted until platelet counts reach } \\
\leq 150 \times 10^{9} / \mathrm{L} \text {, and then } 2.5 \mathrm{mg} \text { was given }\end{array}$ \\
\hline & $5 \mathrm{mg}$ & increase to $7.5 \mathrm{mg}$ & $5 \mathrm{mg}$ & reduce to $3.75 \mathrm{mg}$ & $\begin{array}{l}\text { Dose should be interrupted until platelet counts reach } \\
\leq 150 \times 10^{9} / \mathrm{L} \text {, and then } 3.75 \mathrm{mg} \text { was given }\end{array}$ \\
\hline & $7.5 \mathrm{mg}$ & $7.5 \mathrm{mg}$ & $7.5 \mathrm{mg}$ & reduce to $5 \mathrm{mg}$ & $\begin{array}{l}\text { Dose should be interrupted until platelet counts reach } \\
\leq 150 \times 10^{9} / \mathrm{L} \text {, and then } 5 \mathrm{mg} \text { was given }\end{array}$ \\
\hline
\end{tabular}

All doses were give once daily. 
Table S3 Treatment interruption and dose modification per protocol

\begin{tabular}{|c|c|}
\hline & Patients $(n=37)$ \\
\hline Treatment interruption & $4(10.8 \%)$ \\
\hline \multicolumn{2}{|c|}{ Duration of treatment interruption, days } \\
\hline Median (IQR) & $10.0(8.0-11.0)$ \\
\hline Mean \pm SD & $9.5 \pm 1.9$ \\
\hline \multicolumn{2}{|l|}{ Final dose } \\
\hline $2.5 \mathrm{mg}$ once every other day & $1(2.7 \%)$ \\
\hline 2.5 mg once daily & $4(10.8 \%)$ \\
\hline $3.75 \mathrm{mg}$ once daily & $4(10.8 \%)$ \\
\hline 5 mg once daily & $9(24.3 \%)$ \\
\hline $7.5 \mathrm{mg}$ once daily & $19(51.4 \%)$ \\
\hline \multicolumn{2}{|l|}{ DDose, mg/d } \\
\hline Median (IQR) & $5.9(4.2-6.7)$ \\
\hline Mean \pm SD & $5.5 \pm 1.3$ \\
\hline \multicolumn{2}{|l|}{ Dose adjustment times } \\
\hline 0 & $2(5.4 \%)$ \\
\hline 1 & $22(59.5 \%)$ \\
\hline 2 & 7 (18.9\%) \\
\hline 3 & $2(5.4 \%)$ \\
\hline 4 & $2(5.4 \%)$ \\
\hline 6 & $2(5.4 \%)$ \\
\hline
\end{tabular}

Data are presented as $\mathrm{n}(\%)$, unless otherwise specified. 
Table S4 Treatment-related adverse events

\begin{tabular}{|c|c|c|}
\hline & \multicolumn{2}{|c|}{ Patients $(n=37)$} \\
\hline Any & $13(35.1 \%)$ & $2(5.4 \%)$ \\
\hline Blood lactate dehydrogenase increased & $5(13.5 \%)$ & 0 \\
\hline Alanine aminotransferase increased & $4(10.8 \%)$ & $1(2.7 \%)$ \\
\hline Blood uric acid increased & $2(5.4 \%)$ & 0 \\
\hline Alpha hydroxybutyrate dehydrogenase increased & $1(2.7 \%)$ & 0 \\
\hline Gamma-glutamyltransferase increased & $1(2.7 \%)$ & 0 \\
\hline Bilirubin conjugated increased & $1(2.7 \%)$ & 0 \\
\hline Hyperuricemia & $1(2.7 \%)$ & $1(2.7 \%)$ \\
\hline Decreased appetite & $1(2.7 \%)$ & 0 \\
\hline Somnolence & $1(2.7 \%)$ & 0 \\
\hline Headache & $1(2.7 \%)$ & 0 \\
\hline Face edema & $1(2.7 \%)$ & 0 \\
\hline Fatigue & $1(2.7 \%)$ & 0 \\
\hline Edema peripheral & $1(2.7 \%)$ & 0 \\
\hline Nausea & $1(2.7 \%)$ & 0 \\
\hline
\end{tabular}

Data are presented as $\mathrm{n}(\%)$. The treatment-related adverse events refers to the correlation of the adverse events with study treatment was "definitely related", "possibly related", or "unassessable", as judged by investigators. 